\title{
PREDICTION OF DIFFICULT LAPAROSCOPIC CHOLECYSTECTOMY USING CLINICAL AND ULTRASONOGRAPHY PARAMETERS
}

\author{
Anju Bhagtana ${ }^{1}$, Neelkamal Singh ${ }^{2}$, Anuj Mahajan³, Tejinderpal Singh ${ }^{4}$, Aaina Malhotra ${ }^{5}$
}

${ }_{1}^{1}$ Senior Resident, Department of Surgery, DMC and H, Ludhiana, Punjab.

${ }^{2}$ Medical Officer, Department of Surgery, DMC and H, Ludhiana, Punjab.

3 Senior Resident, Department of Surgery, DMC and H, Ludhiana, Punjab.

${ }^{4}$ Senior Resident, Department of Surgery, Fortis, Ludhiana, Punjab.

5Junior Resident, Department of Anaesthesia, DMC and H, Ludhiana, Punjab.

\section{BACKGROUND}

\section{ABSTRACT}

Laparoscopic cholecystectomy has become the gold standard in the treatment of symptomatic gall stones due to decreased postoperative pain, earlier oral intake, shorter hospital stay, early resumption of normal activity and improved cosmesis. Laparoscopic cholecystectomy may be rendered difficult because of various problems encountered during surgery such as difficult in access to the peritoneal cavity, creation of pneumoperitoneum, gall bladder dissection or extraction of the excised gall bladder. This provoked an interest in studying the factors that could predict the successful completion of the early laparoscopic cholecystectomy.

The aim of this study is to define specific parameters for predicting difficulty of laparoscopic cholecystectomy pre-operatively.

\section{MATERIALS AND METHODS}

We conducted a prospective, observational study on 50 cases of symptomatic cholelithiasis who underwent laparoscopic cholecystectomy at our institute during a period of 1 year. Patients with choledocholithiasis or prior history of partial cholecystectomies and suspicion of malignancy were excluded from the study. Various clinical and radiological parameters were noted and the patients were scored to predict difficulty in surgery. Assessment of the difficulties encountered in terms of duration of surgery, bleeding during surgery, difficult access to peritoneal cavity, gall bladder bed dissection, conversion to open cholecystectomy and post-operative morbidity and hospital stay were noted and results were compared to the pre-operative scores.

\section{RESULTS}

Factors such as age, abdominal scar and BMI had no role in the conversion of laparoscopic cholecystectomy. Prior history of an acute attack, palpable and thickened gall bladder, presence of pericholecystic fluid, impacted stone in gall bladder neck had effect on determining the difficulty of laparoscopic cholecystectomy.

\section{CONCLUSION}

Selection of patients for laparoscopic cholecystectomy is must to avoid all these preventable complications.

\section{KEYWORDS}

Injury during Cholecystectomy, Conversion, Open Cholecystectomy.

HOW TO CITE THIS ARTICLE: Bhagtana A, Singh N, Mahajan A, et al. Prediction of difficult laparoscopic cholecystectomy using clinical and ultrasonography parameters. J. Evolution Med. Dent. Sci. 2018;7(13):1663-1667, DOI: 10.14260/jemds/2018/375

\section{BACKGROUND}

Laparoscopic cholecystectomy has become the gold standard in the treatment of symptomatic cholelithiasis. It has replaced open cholecystectomy as the therapeutic modality of choice in the treatment of cholelithiasis.[1,2,3] Laparoscopic approach has several benefits over the open approach such as decreased post-operative pain, earlier oral intake, shorter hospital stay, early resumption of normal activity and improved cosmesis. $[4,5,6]$

'Financial or Other Competing Interest': None.

Submission 21-01-2018, Peer Review 07-03-2018,

Acceptance 13-03-2018, Published 26-03-2018.

Corresponding Author:

Anju Bhagtana,

\#101 PG Hostel,

DMC and $H$,

Ludhiana, Punjab.

E-mail: anju_bhagtana@rediffmail.com

DOI: $10.14260 /$ jemds $/ 2018 / 375$

\section{(c) $\bigcirc($ ) $\ominus$}

Various problems may be encountered by the surgeon during the procedure such as difficulty in accessing the peritoneal cavity, creating a pneumoperitoneum, dissecting the gall bladder or extracting the excised gall bladder.[7] Laparoscopy has certain technical limitations like the loss of depth perception, a limited and fixed view of operative field, indirect contact with intra-abdominal structures especially while using energy sources and limited tactile feedback during dissection and manipulation of tissues. With the widespread use of laparoscopy for elective cholecystectomies came the interest in studies exploring the safety, benefits and timing of laparoscopic cholecystectomies for symptomatic gall stone disease. This provoked an interest in identifying the factors that could predict the successful completion and difficulty of early laparoscopic cholecystectomy in symptomatic cholelithiasis.[8]

The need for conversion to laparotomy should not be considered a failure or a complication, but rather as an attempt to avoid complication and ensure patient's safety. ${ }^{[9]}$ Therefore, a patient can be prepared psychologically in the scenario of expected difficult cholecystectomy.[10,11] 
This study was undertaken to study the scoring systems that may predict the pre-operative difficulties of laparoscopic cholecystectomy, so that the complication of the procedure may be avoided and decision can be made beforehand to perform open cholecystectomy. We conducted our study to predict the level of difficulty of laparoscopic cholecystectomy by using the scoring method, which was invented by Randhawa and Pujahari.[12]

\section{MATERIALS AND METHODS}

This was a prospective, observational study conducted in Dayanand Medical College and Hospital, Ludhiana, which is a tertiary care institute of North India after obtaining Institutional Review and Ethics Board Approval. 50 patients (Age range 16 - 50 years) who underwent laparoscopic cholecystectomy during a period of 1 year from January 2015 to January 2016 were included in the study.

Patients with choledocholithiasis, prior partial cholecystectomy/ CBD exploration or any suspicion or proven gallbladder malignancy were excluded from the study.

Surgery was done using $\mathrm{CO}_{2}$ pneumoperitoneum with standard two $5 \mathrm{~mm}$ and two $10 \mathrm{~mm}$ ports in all patients after obtaining cardiac clearance in necessary cases. The timing was noted from the first port site incision till the last port closure. All the intraoperative events were recorded. In all the cases who undergo elective laparoscopic cholecystectomy the assessment of the difficulties encountered in terms of duration of surgery (in minutes), bleeding during surgery, difficult access to peritoneal cavity, gall bladder bed dissection, conversion to open cholecystectomy and postoperative morbidity and hospital stay were noted.

The demographic data, clinical and USG parameters of patient were noted. After the workup, the scores were given. The scores were compared using the following comparative data (Table 1).

Pre-operatively, patients were assigned to easy (5), difficult (6-10) or very difficult (11-15).

Difficulty level of laparoscopic cholecystectomy was ascertained according to various parameters (Table 2).

Analysis of pre-operative risk factors, their relation to the dependent factors were performed using appropriate statistical methods, significance was demonstrated in every case $(\mathrm{p} \leq 0.05)$.

The statistical analysis was done using Z-test.

SPSS version 17 was used.

\section{RESULTS}

Out of these 50 laparoscopic cholecystectomies 13 (26\%) were converted to open cholecystectomy, out of which 7 were females. The major reason of conversion was difficult anatomy.

\section{Gender}

Out of total 50, 21 were females and 29 were Males. In our study conversion rate was more in females, but was not statistically significant ( $\mathrm{p}$ value 0.24 ).

\section{Age}

The highest number of population fallen in age group of 4160 years and comparatively more number of cases were converted to open cholecystectomy in this age group (5 out of 22).
There was no significant difference in conversion rates of laparoscopic cholecystectomy with age (Table 1).

\begin{tabular}{|c|c|c|c|}
\hline Age & $\begin{array}{c}\text { Laparoscopic } \\
\text { Cholecystectomy }\end{array}$ & $\begin{array}{c}\text { Open } \\
\text { Cholecystectomy }\end{array}$ & Total \\
\hline$<50$ yrs. & $12(75.0 \%)$ & $4(25 \%)$ & 16 \\
\hline$>50$ yrs. & $25(73.5 \%)$ & $9(26.4 \%)$ & 34 \\
\hline & $37(74 \%)$ & $13(26 \%)$ & 50 \\
\hline \multicolumn{2}{|r|}{ Table 1. Age Distribution of Patient on Study Group } \\
\hline
\end{tabular}

\section{History of Hospitalisation}

Prior history of hospitalisation was taken and patients were divided into two groups. 39 patients had history of hospitalisation, out of which $11(28.2 \%)$ were converted to open cholecystectomy. 11 patients did not have history of hospitalisation and 2 patients (18.1\%) were converted to open cholecystectomy. This factor had the role in increasing the duration of surgery by dense adhesion or failure of anatomy. This factor had effect on conversion rate, but was not statistically significant (p- 0.404).

\section{Body Mass Index}

In our study, we divided patients into 3 groups with body mass index of $<25,25-27.5$ and $>27.5$. The group with body mass index $<25 \%$ had total 9 cases and in which $2(22.2 \%)$ were converted into open cholecystectomy and patients with body mass index $25-27.5$ and $>27.5$ were total 41 in number and collectively 11 (26.8\%) case got converted in open cholecystectomy. Patients with body mass index $>25$ had higher conversion rate as compared to body mass index $<25$. This factor was statistically significant (p- 0.059) (Table 2).

\begin{tabular}{|c|c|c|c|}
\hline $\begin{array}{c}\text { Body Mass } \\
\text { Index }\end{array}$ & $\begin{array}{c}\text { Laparoscopic } \\
\text { Cholecystectomy }\end{array}$ & $\begin{array}{c}\text { Open } \\
\text { Cholecystectomy }\end{array}$ & Total \\
\hline$<25$ & $7(77.7 \%)$ & $2(22.2 \%)$ & 9 \\
\hline $25-27.5$ & $14(73.6 \%)$ & $5(26.3 \%)$ & 19 \\
\hline$>27.5$ & $16(72.7 \%)$ & $6(27.2 \%)$ & 22 \\
\hline \multicolumn{4}{|r|}{ Table 2. Body Mass Index Distribution of Patients } \\
\hline
\end{tabular}

\section{Abdominal Scar}

Patients were divided on the basis of presence of an abdominal scar. 14 (28.0\%) patients (9 females) had scar on abdominal wall and out of which $3(21.4 \%)$ patients were converted to open cholecystectomy. 36 (72.5\%) patients did not have any abdominal scar and out of which 10 (27.5\%) were converted to open cholecystectomy.

Abdominal scar did not have any significant effect of conversion rate, so this factor was not statistically significant (p- 0.471) (Table 3).

\begin{tabular}{|c|c|c|c|}
\hline ABD Scar & $\begin{array}{c}\text { Laparoscopic } \\
\text { Cholecystectomy }\end{array}$ & $\begin{array}{c}\text { Open } \\
\text { Cholecystectomy }\end{array}$ & Total \\
\hline Present & $11(78.5 \%)$ & $3(21.4 \%)$ & 14 \\
\hline $\begin{array}{c}\text { Not } \\
\text { Present }\end{array}$ & $26(72.2 \%)$ & $10(27.7 \%)$ & 36 \\
\hline & $37(74.0 \%)$ & $13(26.0 \%)$ & 50 \\
\hline
\end{tabular}

Table 3. Abdominal Scar Distribution of Patients 


\section{Palpable Gall Bladder}

The patients undergoing laparoscopic cholecystectomy were studied on the basis of palpable gall bladder. Patients with palpable gall bladder had more conversion rate as compared to non-palpable gall bladder, which was statistically significant ( $p$ value- 0.00 ).

\section{Wall Thickness}

Patients with wall thickness $>4 \mathrm{~mm}$ had more conversion rate $(32 \%)$ as compared to thickness $<4 \mathrm{~mm}(20 \%)$. This risk factor had significant effect on conversion rate, but was not statistically significant [p- 0.260].

\section{Pericholecystic Fluid}

14 patients had pericholecystic fluid and out of which 2 (14.2\%) cases got converted to open cholecystectomy. Out of 36 patients with no pericholecystic fluid in USG abdomen, 11 (30.5\%) cases got converted to open cholecystectomy.

This factor was not statistically significant (p- 0.210).

\section{Impacted Stone in Gall Bladder}

21 patients had impacted stone in gall bladder neck, out of which $8(38.0 \%)$ got converted to open cholecystectomy. On other hand, 29 patients did not have impacted stone and out of which $5(17.2 \%)$ patients got converted to open cholecystectomy.

The patients with impacted stone in gall bladder neck had more conversion rate, but this factor was not statistically significant (p- 0.092).

\section{Outcome}

In all patients pre-operative scoring system was used and difficulty of surgery was predicted. Intraoperative findings were compared with pre-operative assessment.

\section{Intraoperative Time Period}

Patients were also compared on the basis of pre-operative score and total duration of surgery. Pre-operative score was found to have a direct correlation with duration of surgery.

Correlation with pre-operative score and intraoperative time was statistically significant (p- 0.024). Successful laparoscopic cholecystectomies for symptomatic gallstones took a mean of 108.65 minute. Procedure requiring conversion to open cholecystectomy, mean intraoperative time was 144.62 and 'p' value of this mean was 0.017 . Hence, the difference in duration of both surgeries was statistically significant.

\section{Total Hospital Stay}

Hospital stay was divided into 3 groups, $1-4$ days, $<7$ days and $>7$ days and scoring system of patient was compared with these groups.

\section{DISCUSSION}

Patient's correlation with pre-operative score and total hospital stay was statistically significant ( $p-0.004)$.

The conversion rate of laparoscopic procedure in this study was $26 \%$ (13 out of 50 patients undergoing laparoscopic cholecystectomy got converted into open cholecystectomy) which was similar to conversion rate reported by Cuschieri A,[13] and Palanivelu C,[14] (15-20\%) and Sakpal et al,[15] (5-10\%) and Ghnnam et al[16] (5\%).

\section{Gender}

In our study majority of patients (29/50) operated were males, but the conversion rate of laparoscopic to open procedure were more for females (33.3\%) as compared to males $(20.6 \%)$, which was found to be statistically nonsignificant. Studies done by Bickel et al[17] and Schafer et al[18] also reported that sex of the patient did not have any significant effect on conversion rate of laparoscopic cholecystectomy.

\section{Age}

Most of our patients were more than 40 years of age. $44 \%$ were in the age group of 41 - 60 years and $40 \%$ were in 61 80 years' age group and had a conversion rate of $22.7 \%$ and $20 \%$ respectively, though this was statistically nonsignificant. This was in contrast to studies by Elder et al,[19] who found age to be a significant independent factor for prediction of conversion rate.

\section{H/O Hospitalisation}

Patients having history of prior hospitalisation had increased conversion rate (28.2\%) as compared to patients who did not have any prior history of hospital admission (18.1\%). This difference was statistically non-significant. Studies done by Elder et al[19] and Randhawa et al[12] found that patients with history of prior hospitalisation had significant increased rate of conversion.

\section{Body Mass Index}

Patients with body mass index $>25$ had higher conversion rate of laparoscopic cholecystectomy $(26.8 \%)$ as compared to patients with body mass index $<25(22.2 \%)$. In our study, body mass index was found to be a statistically significant indicator ( $p-0.059$ ) for conversion of laparoscopic cholecystectomy to open cholecystectomy. Similar study by Randhawa and Pujahari[12] was found that body mass index had significant effect on conversion rate.

\begin{abstract}
Abdominal Scar
Study by Lipman et al[20] found that history of previous abdominal surgery made surgery difficult due to adhesion formation and lead to significant effect on conversion of laparoscopic cholecystectomy to open cholecystectomy. In our study abdominal scar was not found to be a significant factor for conversion to open procedure.
\end{abstract}

\section{Palpable Gall Bladder}

Patients with palpable gall bladder (13/50) had more chances of conversion to open surgery (69.2\%) as compared to patients with a non-palpable gall bladder (10.8\%). This difference was statistically significant in our study. Randhawa and Pujahari[12] found similar results in their study.

\section{Wall Thickness}

Patient who had gall bladder wall thickness > $4 \mathrm{~mm} \mathrm{(50 \% )}$ had more chances of conversion (32\%) as compared to patients with thickness $<4 \mathrm{~mm}(20 \%)$, though this was not significant. In study by Rattner et al,[21] similar results were seen as in our study. 


\section{Pericholecystic Fluid}

Presence of pericholecystic fluid in USG did not have a significant effect on conversion in our study. Out of 14 patients with pericholecystic fluid 2 patients were converted to an open procedure, which was statistically insignificant. Rattner et al[21] also found pericholecystic fluid not to have a significant effect on conversion rate.

\section{Impacted Stone}

Patients with impacted stone (21/50) had more chances of getting converted to open cholecystectomy (38\%). Study by Liu et al and Kama et al[22] also reported that patients with solitary large stone impacted in gall bladder neck were associated with significantly higher chances of conversion to open procedure.

\section{Pre-Operative Score}

In our study, patients with a pre-operative score of $<5$ $(8 / 50)$ had a conversion rate of $25 \%$. Patients with a preoperative score of $6-10(32 / 50)$ had a conversion rate of $21.8 \%$. Out of 10 patients with a pre-operative score of 11 $15,40 \%$ patients were converted. Randhawa and Pujahari[12] in their study found positive predictive value for easy surgery to be $88.8 \%$ and that for difficult procedure to be $92 \%$, (Table 4).

\begin{tabular}{|c|c|c|}
\hline $\begin{array}{c}\text { Pre-Operative } \\
\text { Score }\end{array}$ & $\begin{array}{c}\text { Total Number of } \\
\text { Cases }\end{array}$ & $\begin{array}{c}\text { Converted Cases/ } \\
\text { Conversion Rate }\end{array}$ \\
\hline $0-5$ & 8 & $2(25 \%)$ \\
\hline $6-10$ & 32 & $7(21.8 \%)$ \\
\hline $11-15$ & 10 & $4(40 \%)$ \\
\hline \multicolumn{2}{|c|}{ Score and Conversion Rate } \\
\hline \multicolumn{3}{|c|}{ Table 4. Distribution of Data according to Pre-Operative } \\
\hline
\end{tabular}

\section{Intra-Operative Time}

In our study, laparoscopic cholecystectomy for symptomatic cholelithiasis took a mean of 108.65 minutes. In the converted cases, mean was 144.62. This was found to be statistically significant ( $\mathrm{p}-\mathrm{0}$ 017). These findings were consistent with studies by Lo et al,[23] Elder et al,[19] Schafer et $\mathrm{al}^{[18]}$ Rattner et al[21] and Bickel et al.

\section{Hospital Stay}

In our study, the mean of total hospital stay in laparoscopic cholecystectomy was 7.62 days and 10.69 days in open cholecystectomy patients. This was found to be statistically significant ( $p-0.014)$. This finding was consistent with several studies by Lo et al.[24]

\section{CONCLUSION}

Age had no bearing in the conversion of laparoscopic cholecystectomy. Prior history of an acute attack requiring hospitalisation made surgery difficult due to dense adhesion formation and failure to identify anatomy. Body mass index did have an effect on conversion of laparoscopic cholecystectomy in symptomatic gall stone disease. Abdominal scar did not have any effect on the outcome of surgery. Palpable gall bladder has significant effect on conversion of laparoscopic cholecystectomy. Thickened gall bladder has more chances of conversion. Pericholecystic fluid suggestive of gall bladder having rent or perforation, which makes dissection difficult due to adhesion. Impacted stone in gall bladder neck has effect on conversion of laparoscopic cholecystectomy. Converted laparoscopic cholecystectomy is associated significantly with longer duration of surgery, hospital stay, more scars and morbidity.

Hence, selection of patients for laparoscopic cholecystectomy is must to avoid all these preventable complications.

\section{REFERENCES}

[1] Cuschieri A, Dubois F, Mouiel J, et al. The European experience with laparoscopic cholecystectomy. Am J Surg 1991;161(3):385-7.

[2] Southern Surgeon Club. A prospective analysis of 1518 laparoscopic cholecystectomies. N Engl J Med 1991;324(16):1073-8.

[3] Liu CL, Fan ST, Lai EC, et al. Factors affecting conversion of laparoscopic cholecystectomy to open surgery. Arch Surg 1996;131(1):98-101.

[4] Livingston EH, Rege RV. A nationwide study of conversion from laparoscopic to open cholecystectomy. Am J Surg 2004;188(3):205-11.

[5] Williams LF, Chapman WC, Bonau RA, et al. Comparison of laparoscopic cholecystectomy with open cholecystectomy in a single center. Am J Surg 1993;165(4):459-65.

[6] Kane RL, Lurie N, Borbas C, et al. The outcomes of elective laparoscopic and open cholecystectomies. J Am Coll Surg 1995;180(2):136-45.

[7] Nachnani J, Supe A. Pre-operative prediction of difficult laparoscopic cholecystectomy using clinical and ultrasonographic parameters. Indian J Gastroentral 2005;24(1):16-8.

[8] Gadacz TR. Update on laparoscopic cholecystectomy, including a clinical pathway. Surg Clin North Am 2000;80(4):1127-49.

[9] Kologlu M, Tutuncu T, Yuksek YN, et al. Using a risk score for conversion from laparoscopic to open cholecystectomy in resident training. Surgery 2004;135(3):282-7.

[10] Sanabria JR, Gallinger S, Croxford R, et al. Risk factors in elective laparoscopic cholecystectomy for conversion to open cholecystecomy. J Am Coll Surg 1994;179(6):696-704.

[11] Fried GM, Barkun JS, Sigman HH, et al. Factors determining conversion to laparotomy in patients undergoing laparoscopic cholecystectomy. Am J Surg 1994;167(1):35-41.

[12] Randhawa JS, Pujahari AK. Preoperative prediction of difficult lap chole: a scoring method. Indian J Surg 2009;71(4):198-201.

[13] Cuschieri A. Cholecystitis. In: Blumgart CLH, Fong Y, eds. Surgery of the liver and biliary tract. Vol. 1. $3^{\text {rd }}$ edn. UK: Colon. WB Saunders 2000: p. 667-72.

[14] Palanivelu C. Textbook of laparoscopic surgery. $1^{\text {st }}$ edn. Coimbatore: Gem Digestive Diseases Foundation 2002: p. 147.

[15] Sakpal SV, Bindra SS, Chamberlain RS. Laparoscopic Cholecystectomy conversion rates two decades later. JSLS 2010;14(4):476-83. 
[16] Ghnnam W, Malek J, Shebl E, et al. Rate of conversion and complications of laparoscopic cholecystectomy in a tertiary care center in Saudi Arabia. Ann Saudi Med 2010;30(2):145-8.

[17] Bickel A, Rappaport A, Kanievski V, et al. Laparoscopic management of acute cholecystitis. Surg Endosc 1996;10(11):1045-9.

[18] Schafer M, Krahenbuhl L, Buchler MW. Predictive factors for the type of surgery in acute cholecystitis. Am J Surg 2001;182(3):291-7.

[19] Eldar S, Sabo E, Nash M, et al. Laparoscopic cholecystectomy for acute cholecystitis: prospective trail. World J Surg 1997;21(5):540-5.

[20] Lipman JM, Claridge JA, Haridas M, et al. A modified scoring system to assess difficult laparoscopic cholecystectomy preoperatively. Surgery 2007;142(4):556-63.
[21] Rattner OW, Ferguson C, Warshaw AL. Factors associated with successful laparoscopic cholecystectomy for acute cholecystitis. Ann Surg 1993;217(3):233-6.

[22] Kama Na, Doganay M, Dolapci M, et al. Risk factors resulting in conversion of laparoscopic cholecystectomy to open surgery. Surg Endosc 2001;15(9):965-8.

[23] Lo CM, Fan ST, Liu CL, et al. Early decision for conversion of laparoscopic to open cholecystectomy for treatment of acute cholecystitis. Am J Surg 1997;173(6):513-7. 